Laurence Klotz, Sunnybrook Health Sciences Centre, University of Toronto: Mary Gospodarowicz, Princess Margaret Hospital, Toronto; Chris O'Callaghan and Keyue Ding, Queen's University, Kingston; Shawn Malone, Ottawa Regional Cancer Centre, Ottawa, Ontario; Paul Toren, Larry Goldenberg, and Juanita M. Crook, University of British Columbia, Vancouver, British Columbia, Canada; David Dearnaley, Royal Marsden Hospital, London, United Kingdom; Celestia S. Higano, Fox Chase Cancer Center, Philadelphia, PA; and Eric Horwitz, University of Washington and Fred Hutchinson Cancer Research Center, Seattle, WA

Published online ahead of print at www.jco.org on March 2, 2015.

Supported by the Canadian Cancer Society Research Institute, National Cancer Institute, and National Institutes of Health Royal Marsden Institute for Cancer Research Biomedical Research Centre.

Authors' disclosures of potentia conflicts of interest are found in the article online at www.jco.org. Author contributions are found at the end of this article.

Clinical trial information: NCT00003653.

Corresponding author: Laurence Klotz, MD, FRCSC, University of Toronto, Division of Urology, Sunnybrook Health Sciences Centre, 2075 Bayview Ave, \#MG408, Toronto, Ontario M4N 3M5

Canada; e-mail: laurence.klotz

@sunnybrook.ca.

(C) 2015 by American Society of Clinical Oncology

0732-183X/15/3310w-1151w/\$20.00 DOI: 10.1200/JCO.2014.58.2973

\title{
Nadir Testosterone Within First Year of Androgen- Deprivation Therapy (ADT) Predicts for Time to Castration-Resistant Progression: A Secondary Analysis of the PR-7 Trial of Intermittent Versus Continuous ADT
}

Laurence Klotz, Chris O'Callaghan, Keyue Ding, Paul Toren, David Dearnaley, Celestia S. Higano, Eric Horwitz, Shawn Malone, Larry Goldenberg, Mary Gospodarowicz, and Juanita M. Crook

See accompanying editorial on page 1098

$$
\begin{array}{llllllll}
\text { A } & \text { B } & \text { S } & \text { T } & \text { R } & \text { A } & \text { C } & \text { T }
\end{array}
$$

\section{Purpose}

Three small retrospective studies have suggested that patients undergoing continuous androgen deprivation (CAD) have superior survival and time to progression if lower castrate levels of testosterone $(<0.7 \mathrm{nmol} / \mathrm{L})$ are achieved. Evidence from prospective large studies has been lacking.

\section{Patients and Methods}

The PR-7 study randomly assigned patients experiencing biochemical failure after radiation therapy or surgery plus radiation therapy to CAD or intermittent androgen deprivation. The relationship between testosterone levels in the first year and cause-specific survival (CSS) and time to androgen-independent progression in men in the CAD arm was evaluated using Cox regression.

\section{Results}

There was a significant difference in $\operatorname{CSS}(P=.015)$ and time to hormone resistance $(P=.02)$ among those who had first-year minimum nadir testosterone $\leq 0.7,>0.7$ to $\leq 1.7$, and $\geq 1.7$ $\mathrm{nmol} / \mathrm{L}$. Patients with first-year nadir testosterone consistently $>0.7 \mathrm{nmol} / \mathrm{L}$ had significantly higher risks of dying as a result of disease $(0.7$ to $1.7 \mathrm{nmol} / \mathrm{L}$ : hazard ratio $[\mathrm{HR}], 2.08 ; 95 \% \mathrm{Cl}, 1.28$ to $3.38 ;>1.7 \mathrm{nmol} / \mathrm{L}: \mathrm{HR}, 2.93 ; 95 \% \mathrm{Cl}, 0.70$ to 12.30$)$ and developing hormone resistance $(0.7$ to $1.7 \mathrm{nmol} / \mathrm{L}: \mathrm{HR}, 1.62 ; 95 \% \mathrm{Cl}, 1.20$ to $2.18 ; \geq 1.7 \mathrm{nmol} / \mathrm{L}: \mathrm{HR}, 1.90 ; 95 \% \mathrm{Cl}, 0.77$ to 4.70$)$. Maximum testosterone $\geq 1.7 \mathrm{nmol} / \mathrm{L}$ predicted for a higher risk of dying as a result of disease $(P=.02)$.

\section{Conclusion}

Low nadir serum testosterone (ie, $<0.7 \mathrm{mmol} / \mathrm{L}$ ) within the first year of androgen-deprivation therapy correlates with improved CSS and duration of response to androgen deprivation in men being treated for biochemical failure undergoing CAD.

\section{J Clin Oncol 33:1151-1156. (C) 2015 by American Society of Clinical Oncology}

\section{INTRODUCTION}

The goal of androgen-deprivation therapy (ADT) in men with recurrent or advanced prostate cancer, first described 70 years ago, is to reduce serum testosterone to castrate levels, inducing regression of the disease. ${ }^{1}$ It has recently been recognized that luteinizing hormone-releasing hormone (LHRH) analogs result in a heterogeneous testosterone response. ${ }^{2}$ The upper level of testosterone considered castrate varies between 0.7 and $1.7 \mathrm{nmol} / \mathrm{L}$ (ie, 20 to $50 \mathrm{ng} / \mathrm{dL}$ ). Although virtually all patients experience a substantial reduction in testosterone, the hormone levels vary from subcastrate $(\leq 0.7 \mathrm{nmol} / \mathrm{L})$ to sup- racastrate ( $\geq 1.7 \mathrm{nmol} / \mathrm{L})$. Furthermore, breakthrough of testosterone in men receiving continuous LHRH agonists, defined as any rise $>$ $1.7 \mathrm{nmol} / \mathrm{L}$ level, is commonly reported, occurring in up to $13 \%$ of patients. ${ }^{3}$ Three small retrospective studies have suggested that patients undergoing continuous androgen deprivation (CAD) have superior survival and time to progression if lower castrate levels of testosterone $(\leq 0.7 \mathrm{nmol} / \mathrm{L})$ are achieved. $^{4-6}$ These studies consisted of a mixed population of patients, many of whom had short followup. The studies were also based on a single testosterone determination, usually after 6 months of ADT. High-quality evidence from prospective, 
large studies based on serial testosterone levels after ADT demonstrating a relationship between nadir testosterone value and time to progression and prostate cancer survival is lacking.

Intermittent ADT (IAD), first described in $1986,{ }^{7}$ has been studied intensively over the last 20 years. In men receiving intermittent therapy, ADT is stopped after 6 to 9 months, and testosterone and prostate-specific antigen (PSA) levels are allowed to rise to predetermined arbitrary thresholds, at which point ADT is resumed. Evidence from 18 phase II studies and several phase III studies has suggested that IAD is safe. ${ }^{8}$ The landmark NCIC Clinical Trials Group PR-7 study, recently published, ${ }^{9}$ was designed to demonstrate whether IAD is noninferior to $\mathrm{CAD}$ with respect to overall survival in men experiencing nonmetastatic biochemical recurrence after radiation therapy or surgery followed by radiation therapy. Of 1,386 enrolled patients, 690 were randomly assigned to intermittent therapy and 696 to continuous therapy. Median follow-up was 6.9 years. There were no significant between-group differences in adverse events. In the IAD group, full testosterone recovery occurred in $35 \%$ of patients, and testosterone recovery to the trial-entry threshold (ie, $>5 \mathrm{nmol} / \mathrm{L}$ ) occurred in $79 \%$. Intermittent therapy provided potential quality-of-life benefits with respect to physical function, fatigue, urinary problems, hot flushes, libido, and erectile function. There were 268 deaths in the IAD group and 256 in the CAD group. Median overall survival was 8.8 years in the IAD group versus 9.1 years in the CAD group (hazard ratio [HR] for death, 1.02; 95\% CI, 0.86 to 1.21). Estimated 7-year cumulative rates of disease-related death were $18 \%$ and $15 \%$ in the two groups, respectively $(P=.24)$.

The CAD arm of the PR-7 study, consisting of 626 evaluable patients receiving ADT for a median of 8 years, represented an ideal opportunity to address the relationship between nadir testosterone level and disease progression. Our primary hypothesis was that in patients undergoing $\mathrm{CAD}$, a higher nadir testosterone value in the first year of ADT would correlate with a reduced time to development of castration-resistant prostate cancer and lower causespecific survival (CSS).

\section{PATIENTS AND METHODS}

The PR-7 study was opened in Canada in 1999, supported by the Southwest Oncology Group (SWOG), Radiation Therapy Oncology Group, Cancer Tri- als Support Unit, and Institute of Cancer Research Clinical Trials and Statistics Unit (United Kingdom). Study drugs were prescribed according to usual practice at each participating institution. Men with histologically confirmed adenocarcinoma of the prostate were eligible for the study if they had completed definitive radiotherapy (primary or salvage) $>12$ months before enrollment, had a rising PSA level $>3 \mathrm{ng} / \mathrm{mL}$ that was higher than the post-radiation therapy nadir, and had no evidence of distant metastasis on computed tomography or bone scan. Prior ADT for up to 12 months in association with definitive treatment was permitted if it was completed $\geq 12$ months before enrollment. Baseline serum testosterone level had to be $>5$ $\mathrm{nmol} / \mathrm{L}$ (ie, $144 \mathrm{ng} / \mathrm{dL}$ ). Patients were randomly assigned at a one-to-one ratio to the two treatment groups. CAD consisted of orchiectomy or an LHRH agonist, combined with a nonsteroidal antiandrogen, with the latter continued for a minimum of 4 weeks. IAD consisted of 8 months of an LHRH agonist and at least 4 weeks of a nonsteroidal antiandrogen, followed by a variable time off $\mathrm{ADT}$ as determined by the rise in PSA to $10 \mathrm{ng} / \mathrm{mL}$ (or to baseline value if $<10$ $\mathrm{ng} / \mathrm{mL}$ at study entry). Time to castration-resistant prostate cancer (CRPC) was calculated for all patients from the day of random assignment to the date CRPC was first documented. CRPC was defined as three successive increases in PSA ( $\geq 1$ month apart and during treatment), with the highest PSA $>4$ $\mathrm{ng} / \mathrm{mL}$, and/or new evidence of clinical disease, with castrate level of testosterone $(<3 \mathrm{nmol} / \mathrm{L}$ [ie, $85 \mathrm{ng} / \mathrm{dL}])$ measured within 1.5 months ( 6 weeks) of the qualifying event. Testosterone was evaluated every 2 months, and PSA every 2 months. After development of CRPC, management was determined by the local investigator. The primary end point was overall survival. Secondary end points included time to CRPC and quality of life.

Disease-specific survival was calculated from the date of random assignment to the date of death resulting from prostate cancer or a complication of cancer treatment. The record of each patient who died was reviewed by three investigators to confirm cause of death.

For this analysis, all patients randomly assigned to the CAD arm of the PR-7 trial with at least three testosterone levels recorded during the first 12 months of the study were included, excluding only those who did not actually undergo CAD or had inconsistent dosing or insufficient testosterone assessment. On the basis of the minimum, median, and maximum levels of serum testosterone during the first year of study participation, patients fell into three groups prespecified by serum testosterone levels $\leq 0.7,>0.7$ to $<1.7$, and $\geq 1.7 \mathrm{nmol} / \mathrm{L}$. Baseline factors were age (continuous), Eastern Cooperative Oncology Group performance status ( $0 v 1)$, Gleason score ( $<7 v 7 v>7 v$ missing), prior radical prostatectomy (no $v$ yes), PSA (3 to $15 v>15 \mathrm{ng} / \mathrm{mL}$ ), and time since completion of radical radiotherapy (1 to $3 v>3$ years).

Exploratory analyses were performed to characterize the relationships between patients' serum testosterone levels (during first year of study) with baseline characteristics and outcomes. $\chi^{2}$ test was used to assess association between categorical variables; analysis of variance was used to test association of continuous factors with the three serum testosterone levels; Kaplan-Meier

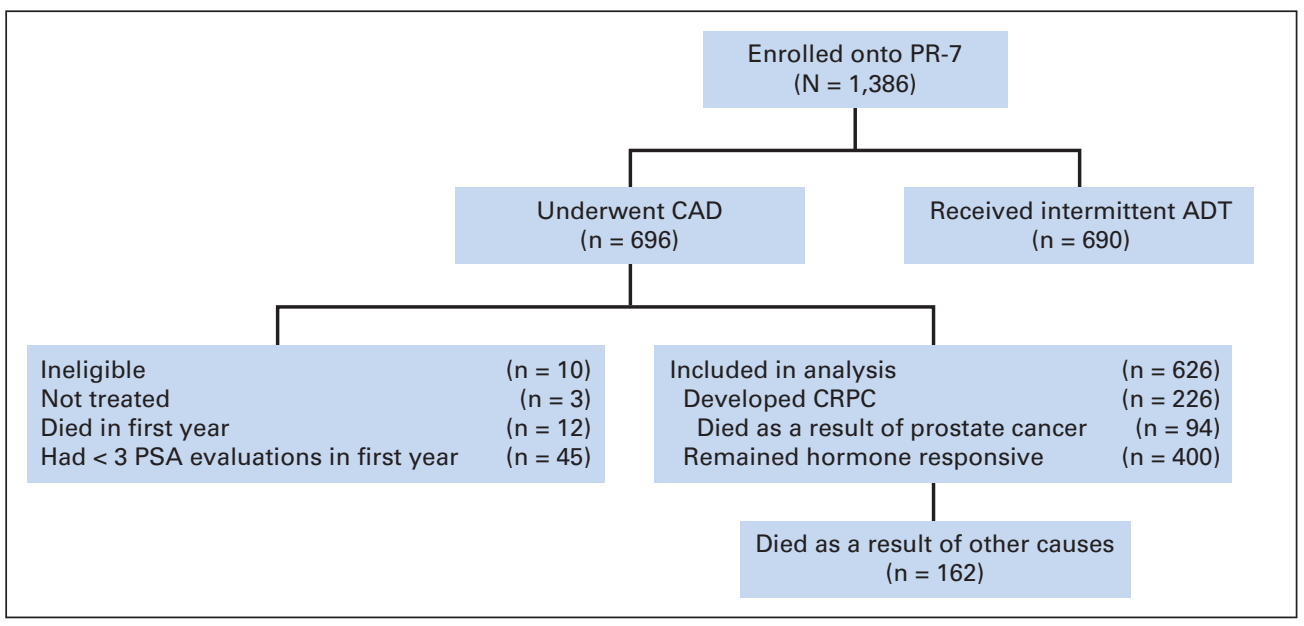

Fig 1. PR-7 CONSORT diagram. ADT, androgen-deprivation therapy; $C A D$, continuous androgen deprivation; CRPC, castration-resistant prostate cancer; PSA, prostate-specific antigen. 
curves were used to estimate distributions of the time to event outcomes; likelihood ratio test based on Cox regression model, adjusting for potential confounding factors, was used to check whether the serum testosterone levels during the first year of study could predict CSS and time to development of CRPC. The Hochberg ${ }^{10}$ procedure was used to adjust $P$ values for these three comparisons. HRs were estimated from Cox regression models. All reported $P$ values are two sided, and $P$ value $<.05$ was considered statistically significant. Analyses were performed using SAS software (version 9.3; SAS Institute, Cary, NC).

\section{RESULTS}

Cohort demographics were described in the original publication of this study. ${ }^{8}$ A total of 1,386 patients entered the PR-7 study, of whom 690 were randomly assigned to IAD and 696 to CAD. Disposition of these patients is described in the CONSORT diagram (Fig 1). Of the total 696 patients in the CAD arm, 626 were eligible for this analysis, of whom 226 developed CRPC. Median time to CRPC was 10.0 years (95\% CI, 8.72 to not estimable); 5-year event-free rate was 69\% (95\% CI, $65 \%$ to $72 \%)$.

Serum testosterone measurement was mandated every 2 months in the first year of the trial; $93 \%$ of patients had serum testosterone assayed $\geq$ three times in year 1 , and these served as the basis for the primary analysis. Distribution of nadir, median, and maximum testosterone levels during the first year of therapy is summarized in Table 1. Nadir testosterone of $\leq 0.7,>0.7$ to $<1.7$, and $\geq 1.7 \mathrm{nmol} / \mathrm{L}$ was achieved in $78 \%, 21 \%$, and $1 \%$ of patients, respectively. Median testosterone level was $\leq 0.7,>0.7$ to $<1.7$, and $\geq 1.7 \mathrm{nmol} / \mathrm{L}$ in $53 \%$, $42 \%$, and $5 \%$ of patients, respectively. Maximum testosterone level was $\leq 0.7,>0.7$ to $<1.7$, and $\geq 1.7 \mathrm{nmol} / \mathrm{L}$ in $27 \%, 50 \%$, and $23 \%$ of patients, respectively. Nadir testosterone during the first year was associated with age $(P<.001)$, with the lowest nadir testosterone associated with older age. Testosterone level during ADT did not significantly correlate with Eastern Cooperative Oncology Group, Gleason score, baseline PSA, or prior radical prostatectomy.

There was a significant difference among the three testosterone groups in time to CRPC $(P=.015$; Table 2; Figs $2 \mathrm{~A}$ to $2 \mathrm{C})$. Patients who did not achieve nadir testosterone $\leq 0.7 \mathrm{nmol} / \mathrm{L}$ had a significantly higher risk of developing CRPC ( 0.7 to 1.7 nmol/L: HR, 1.62;

\begin{tabular}{|c|c|c|c|c|c|c|c|c|}
\hline \multicolumn{9}{|c|}{$\begin{array}{l}\text { Table 1. Distribution of Minimum, Median, and Maximum First-Year } \\
\text { Testosterone Levels and Median Age at Each Level }\end{array}$} \\
\hline \multirow[b]{3}{*}{ Variable } & \multicolumn{8}{|c|}{ Testosterone (nmol/L) } \\
\hline & \multicolumn{2}{|c|}{$\leq 0.7$} & \multicolumn{2}{|c|}{0.7 to 1.7} & \multicolumn{2}{|c|}{$\geq 1.7$} & \multicolumn{2}{|c|}{ Total } \\
\hline & Level & $\%$ & Level & $\%$ & Level & $\%$ & Level & $\%$ \\
\hline \multicolumn{9}{|l|}{$\begin{array}{l}\text { Testosterone } \\
\text { level during } \\
\text { ADT }\end{array}$} \\
\hline Minimum & 489 & 78 & 129 & 21 & 8 & 1 & 626 & 100 \\
\hline Median & 330 & 53 & 265 & 42 & 31 & 5 & 626 & \\
\hline Maximum & 171 & 27 & 310 & 50 & 145 & 23 & 626 & \\
\hline $\begin{array}{l}\text { Mean age, years } \\
\qquad P\end{array}$ & \multicolumn{2}{|c|}{74.3} & \multicolumn{2}{|c|}{72.4} & \multicolumn{2}{|c|}{69.6} & \multicolumn{2}{|c|}{$\begin{array}{c}73.2 \\
<.001^{*}\end{array}$} \\
\hline $\begin{array}{l}\text { Abbreviation: ADT } \\
\text { *Analysis of variar }\end{array}$ & $\begin{array}{l}\text { androg } \\
\text { test. }\end{array}$ & -de & vation & her & & & & \\
\hline
\end{tabular}

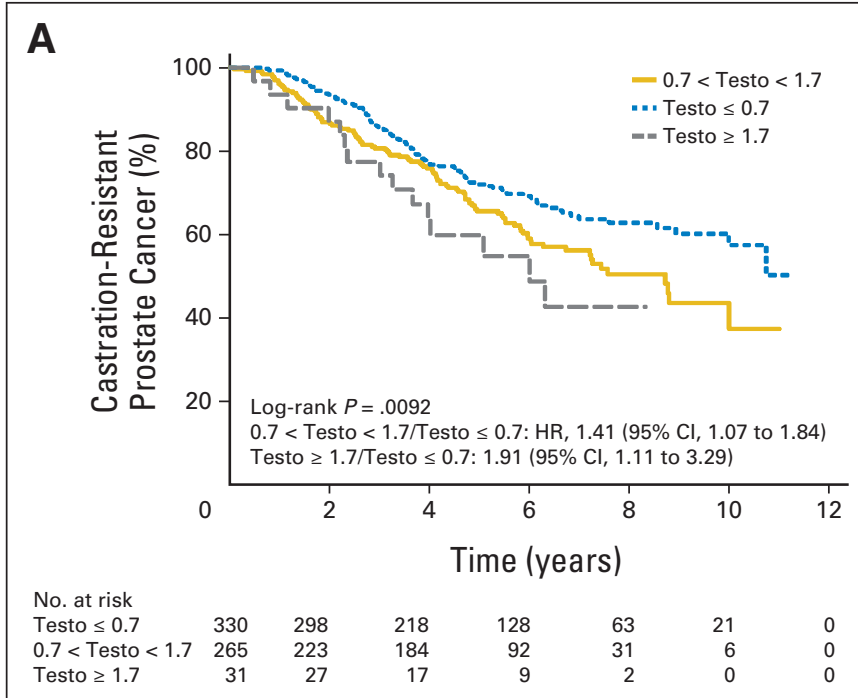

B
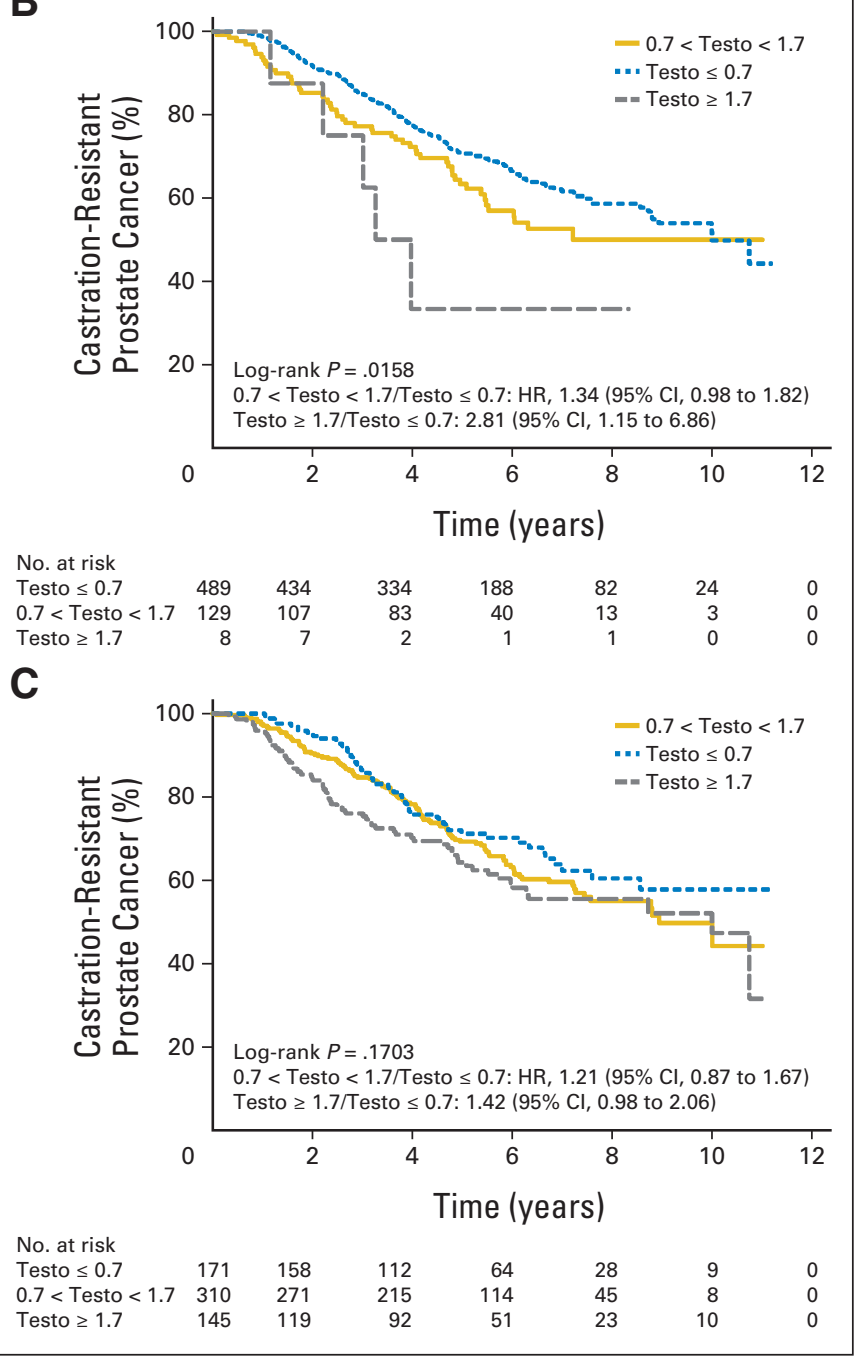

Fig 2. Time to castration-resistant prostate cancer according to $(A)$ median, $(B)$ nadir, and (C) maximum first-year testosterone (testo) levels. HR, hazard ratio. 


\begin{tabular}{|c|c|c|c|c|c|c|c|c|c|c|c|}
\hline \multirow[b]{2}{*}{ Testosterone Level (nmol/L) } & \multirow{2}{*}{$\begin{array}{l}\text { No. of } \\
\text { Patients }\end{array}$} & \multicolumn{5}{|c|}{ Time to CRPC } & \multicolumn{5}{|c|}{ Time to Death Resulting From Prostate Cancer } \\
\hline & & Median (years) & $\mathrm{HR}$ & $95 \% \mathrm{Cl}$ & $P^{*}$ & $P \dagger$ & Median (years) & $H R$ & $95 \% \mathrm{Cl}$ & $P^{*}$ & $P+$ \\
\hline Minimum & & & & & .005 & .015 & & & & .01 & .02 \\
\hline$<0.7$ & 489 & 10.00 & 1 & & & & NR & 1 & & & \\
\hline 0.7 to 1.7 & 129 & 7.21 & 1.62 & 1.20 to 2.18 & & & 10.07 & 2.08 & 1.28 to 3.38 & & \\
\hline$>1.7$ & 8 & 3.62 & 1.90 & 0.98 to 4.70 & & & NR & 2.93 & 0.70 to 12.30 & & \\
\hline Median & & & & & .01 & .02 & & & & .27 & .27 \\
\hline$<0.7$ & 330 & NR & 1 & & & & NR & 1 & & & \\
\hline 0.7 to 1.7 & 265 & 8.72 & 1.34 & 1.04 to 1.75 & & & NR & 1.29 & 0.83 to 2.00 & & \\
\hline$>1.7$ & 31 & 6.00 & 1.97 & 1.18 to 3.26 & & & 6.00 & 1.86 & 0.82 to 4.21 & & \\
\hline Maximum & & & & & .03 & .03 & & & & .01 & .02 \\
\hline$<0.7$ & 171 & NR & 1 & & & & NR & 1 & & & \\
\hline 0.7 to 1.7 & 310 & 8.93 & 1.13 & 0.83 to 1.55 & & & NR & 1.05 & 0.62 to 1.78 & & \\
\hline$>1.7$ & 145 & 10.00 & 1.59 & 1.12 to 2.25 & & & NR & 2.08 & 1.19 to 3.65 & & \\
\hline \multicolumn{12}{|c|}{$\begin{array}{l}\text { Abbreviations: CAD, continuous androgen deprivation; CRPC, castration-resistant prostate cancer; CSS, cause-specific survival; HR, hazard ratio; NR, not reached. } \\
\text { *Likelihood ratio test adjusted for age, time from completion of radiation therapy, Eastern Cooperative Oncology Group performance status, Gleason score, prior } \\
\text { prostatectomy, and baseline testosterone level. } \\
\text { †Adjusted for multiple tests based on Hochberg }\end{array}$} \\
\hline
\end{tabular}

95\% CI, 1.20 to 2.18 ; $\geq 1.7 \mathrm{nmol} / \mathrm{L}: \mathrm{HR}, 1.90 ; 95 \%$ CI, 0.778 to 4.70$)$. Similarly, those patients with a median testosterone level $>0.7$ $\mathrm{nmol} / \mathrm{L}$ had a higher risk of developing CRPC $(P=.02 ; 0.7$ to 1.7 nmol/L: HR, $1.34 ; 95 \%$ CI, 1.04 to $1.75 ; \geq 1.7 \mathrm{nmol} / \mathrm{L}: \mathrm{HR}, 1.97 ; 95 \%$ CI, 1.18 to 3.26). Those who had evidence of breakthrough, with a maximum testosterone level $>0.7 \mathrm{nmol} / \mathrm{L}$, trended to more rapid progression to CRPC, but this did not achieve significance, with an estimated HR of 1.13 (95\% CI, 0.83 to 1.55 ) for maximum serum testosterone between 0.7 to $1.7 \mathrm{nmol} / \mathrm{L}$. Maximum testosterone level $\geq 1.7 \mathrm{nmol} / \mathrm{L}$ was associated with a significantly higher rate of progression to CRPC, with an HR of 1.59 (95\% CI, 1.12 to $2.21 ; P=.03$ ), compared with those with maximum testosterone $\leq 0.7 \mathrm{nmol} / \mathrm{L}$.

CSS was significantly different among the three groups $(P=.02)$. Patients with nadir (minimum) testosterone $>0.7 \mathrm{nmol} / \mathrm{L}$ had a significantly higher risk of dying as a result of disease $(0.7$ to 1.7 nmol/L: HR, 2.08; 95\% CI, 1.28 to $3.38 ; \geq 1.7 \mathrm{nmol} / \mathrm{L}: \mathrm{HR}, 2.93 ; 95 \%$ CI, 0.70 to 12.30 ). Maximum tesosterone $\geq 1.7 \mathrm{nmol} / \mathrm{L}$ also predicted for higher prostate cancer mortality ( $P=.024$; Table 2; Figs 3A to 3C).

An exploratory analysis of minimum, median, and maximum testosterone levels as continuous variables ( $v$ quantized as $\leq 0.7,0.7$ to 1.7 , and $\geq 1.7 \mathrm{nmol} / \mathrm{L}$ ) produced similar results with respect to time to CRPC and CSS. A sensitivity analysis including men with $\geq$ two measurements of testosterone was also performed and yielded similar results (data not shown).

Time from CRPC to death did not correlate with median or maximum testosterone level. However, patients with nadir testosterone $\geq 1.7 \mathrm{nmol} / \mathrm{L}$ had a shorter time from CRPC to death compared with groups with better testosterone suppression $(\geq 1.7 v \leq 0.7$ nmol/L: HR, 2.8; 95\% CI, 1.15 to 8.86 ).

Univariable analysis demonstrated that baseline PSA and Gleason score $>7$ correlated with time to CRPC, and age, Gleason score, and baseline PSA correlated with CSS. There was no correlation between baseline testosterone and either time to CRPC or CSS.

For comparison, an analysis of the relationship between serum testosterone in the first 8 months of ADT was performed in the IAD cohort. Distribution of nadir, median, and maximum testosterone values was similar. A similar correlation was found between time to
CRPC and median testosterone level ( $P=.03$; data not shown). There were no correlations between minimum and maxiumum serum testosterone levels and time to CRPC or CSS. This lack of correlation in the IAD group likely reflects the increased heterogeneity of the IAD cohort with respect to duration of off-treatment intervals, number of cycles, and rate of testosterone recovery off treatment.

\section{DISCUSSION}

This analysis demonstrates that testosterone levels achieved by ADT in the first year correlate with the time to CRPC. Many patients receiving LHRH agonists do not achieve complete testosterone suppression compared with those undergoing surgical castration, which generally results in serum testosterone $<0.7 \mathrm{nmol} / \mathrm{L}$. ${ }^{11}$ A recent review found that up to $12.5 \%$ of patients do not reach the $1.7 \mathrm{nmol} / \mathrm{L}$ ( $50 \mathrm{ng} / \mathrm{dL}$ ) serum testosterone target, and up to $37.5 \%$ do not attain levels $<0.7 \mathrm{nmol} / \mathrm{L}(20 \mathrm{ng} / \mathrm{dL})$. In a 3-year observational study, serum testosterone was monitored every 6 months in 73 patients with prostate cancer starting therapy with three depot formulations of LHRH agonists per month between 2001 and 2003. ${ }^{2}$ At 6 months after start of LHRH analog, 39.7\% had not achieved serum testosterone $<0.7 \mathrm{nmol} / \mathrm{L}$, and $12.3 \%$ had not reached $<1.7$ $\mathrm{nmol} / \mathrm{L}$. Higher testosterone levels after ADT were linked to poorer survival, and patients with elevations $>1.7 \mathrm{nmol} / \mathrm{L}$ seemed to benefit from further blockade of the androgen receptor with the addition of bicalutamide to LHRH agonist therapy. ${ }^{4}$

Skepticism about these earlier results was warranted. It is widely accepted that intracrine synthesis of androgens by prostate cancer cells with autocrine stimulation is a primary mechanism for CRPC. ${ }^{12} \mathrm{Un}$ der such circumstances, one might anticipate that low levels of circulating androgen would be unlikely to have a significant clinical impact. Second, the PR-7 study showed noninferiority of intermittent therapy compared with CAD for survival. The SWOG 9384 study of metastatic prostate cancer comparing IAD with CAD had inconclusive results. ${ }^{13}$ In men receiving intermittent therapy, testosterone level rises during the off-treatment interval. The apparent absence of an adverse effect of 


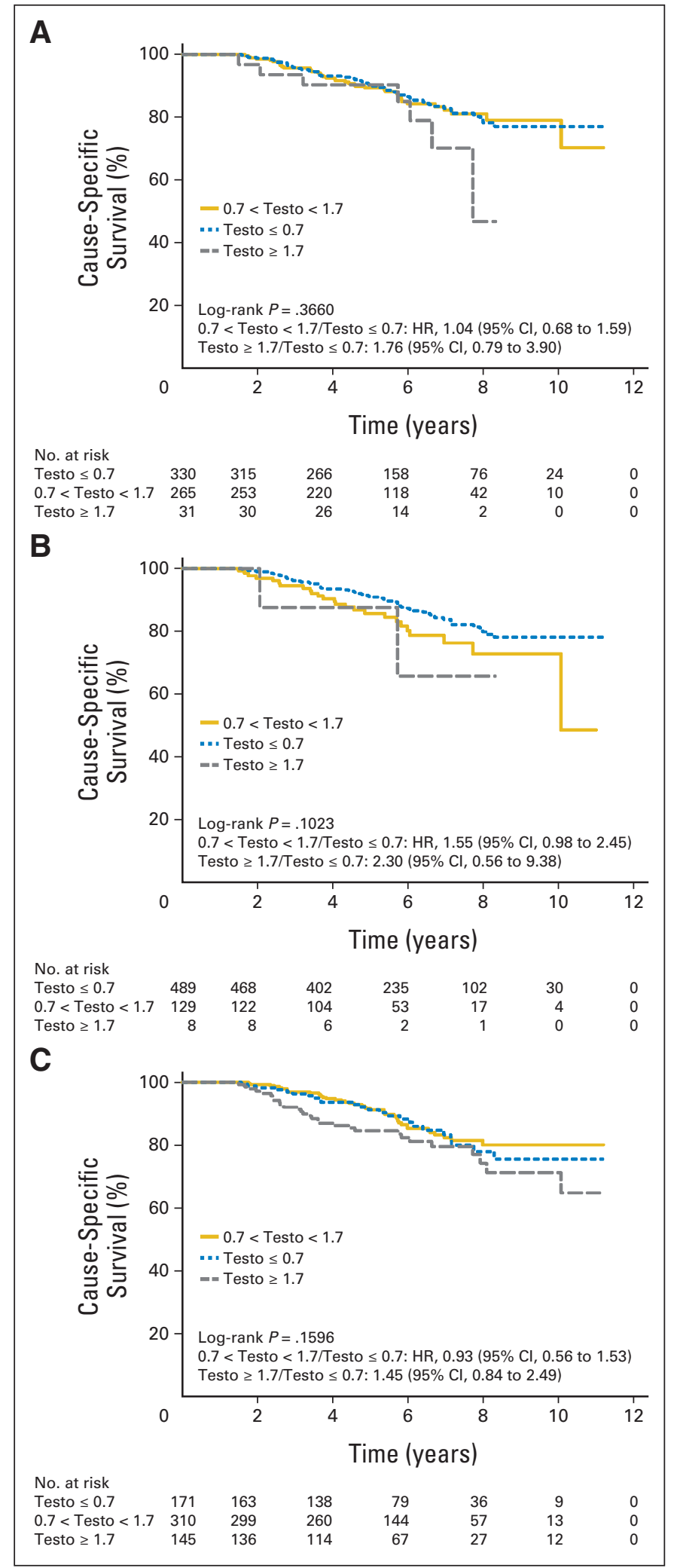

Fig 3. Cause-specific survival according to (A) median, (B) nadir, and (C) maximum first-year testosterone (testo) levels. HR, hazard ratio. intermittent therapy on time to progression might be interpreted as inferring that the impact of serum testosterone during ADT is minor. However, this analysis of PR-7 confirms conclusively that, for men receiving continuous therapy, achieving serum testosterone $<0.7$ $\mathrm{nmol} / \mathrm{L}$ is associated with an improved outcome.

The apparent conundrum of the PR-7 study showing no difference in survival between IAD (where serum testosterone is allowed to rise to normal levels during off-treatment interval), and CAD and the current data showing that low levels of serum testosterone in the first year in the continuous arm correlate with time to progression is problematic. Why should the testosterone level matter in men receiving continuous therapy, if intermittent therapy achieves the same prostate cancer survival (in nonmetastatic disease)? One explanation is that low levels of testosterone during ADT are important in the induction phase of IAD, but it is not necessary to sustain these low levels throughout the course of treatment. This concept is supported by the observation that prostate cancer cells are heterogeneous in their response to ADT. In preclinical models, some prostate cells are maximally proliferative at the same concentration of R1881 that is maximally inhibitory to other cells. ${ }^{14}$ Thus, in vivo, it is plausible that unless testosterone is driven to low levels during induction therapy, partially resistant cells may persist and lead to earlier androgen resistance. This concept was described in more detail in a recent review article. ${ }^{15} \mathrm{~A}$ second possibility is that in fact, intermittent therapy provides a worse outcome with respect to prostate cancer. Both the PR-7 and SWOG 9346 studies showed a nonsignificant trend in this direction; in the case of PR-7, this was balanced by an increase in non-prostate cancer deaths. These trends did not reach significance, which may reflect the lack of power of these large studies to show a small difference in cancer survival. Therefore, they are indeterminate with respect to this question.

The clinical implications of these data are significant. Patients initiating ADT should have their testosterone and PSA levels monitored regularly during the first year of treatment. Testosterone should be assayed just before the next LHRH injection to ensure a sustained response through the dosing interval. Not achieving testosterone $<0.7 \mathrm{nmol} / \mathrm{L}$ during ADT on successive measurements within the first year warrants consideration of a change in hormone therapy, either to another LHRH agonist, to an antagonist, or to bilateral orchiectomy (if continuous therapy is intended). It is also plausible that an antiandrogen added to the LHRH agonist may compensate for higher levels of testosterone, as suggested by Morote et $\mathrm{al}^{4}$; however, this remains unproven.

To confirm the robustness of the observation in patients in the CAD arm, we performed a similar analysis based on serum testosterone during the first 8 months of induction ADT in men receiving intermittent therapy. Median serum testosterone also correlated with time to CRPC, but there was no significant correlation between minimum or maximum testosterone level and time to CRPC, nor was there any correlation with CSS. Analysis of the relationship between testosterone level during treatment and disease progression in the IAD cohort will be the subject of a subsequent report.

The strengths of this study include the size, the prospective nature of the data collection, the prespecified nature of the analysis, and the duration of follow-up. The study also has some limitations. Serum testosterone was performed at the local laboratories rather than a central laboratory; hence, different testosterone assays were used. In 
most cases, testosterone was measured by immunoassay rather than mass spectrometry. This is likely to have introduced an element of variation. Total testosterone was measured, rather than bioavailable or free testosterone. Although testosterone was evaluated close to the end of each period of depot LHRH administration, there was likely some variation in the timing of testosterone assays. The PR-7 study was not designed to test the relationship between serum testosterone during ADT and outcome. It is possible that covariates associated with the higher testosterone levels were responsible for the worse outcome in those patients. Because of the nature of the study, there was no independent validation set. Analysis was performed on serum testosterone levels in the first year of ADT only. Thus, no firm conclusions about the importance of testosterone levels beyond year 1 of ADT can be drawn. The study was observational; although serum testosterone $<0.7 \mathrm{nmol} / \mathrm{L}$ correlated favorably with outcome, we did not formally test the hypothesis that efforts to reduce testosterone in those with levels $>0.7 \mathrm{nmol} / \mathrm{L}$ would improve outcome. In conclusion, our study demonstrates that serum testosterone $\leq 0.7 \mathrm{nmol} / \mathrm{L}$ during the first year of ADT predicts for an improved duration of response in men undergoing $\mathrm{CAD}$ for biochemical failure.

\section{AUTHORS' DISCLOSURES OF POTENTIAL CONFLICTS} OF INTEREST

Disclosures provided by the authors are available with this article at www.jco.org.

\section{AUTHOR CONTRIBUTIONS}

Conception and design: Laurence Klotz, Keyue Ding, Paul Toren, David Dearnaley, Celestia S. Higano, Eric Horwitz, Shawn Malone, Larry

Goldenberg, Juanita M. Crook

Administrative support: Chris O'Callaghan

Provision of study materials or patients: Laurence Klotz

Collection and assembly of data: Laurence Klotz, Chris O'Callaghan, Keyue Ding, David Dearnaley, Celestia S. Higano, Eric Horwitz, Shawn Malone, Larry Goldenberg, Mary Gospodarowicz

Data analysis and interpretation: Laurence Klotz, Chris O'Callaghan, Keyue Ding, Paul Toren, Celestia S. Higano, Shawn Malone, Juanita M. Crook

Manuscript writing: All authors

Final approval of manuscript: All authors

\section{REFERENCES}

1. Huggins C, Hodges CV: Studies on prostatic cancer: I. The effect of castration, of estrogen and of androgen injection on serum phosphatases in metastatic carcinoma of the prostate-1941. J Urol 168:9-12, 2002

2. Morote J, Planas J, Salvador C, et al: Individual variations of serum testosterone in patients with prostate cancer receiving androgen deprivation therapy. BJU Int 103:332-335, 2009

3. Pickles T, Hamm J, Morris WJ, et al: Incomplete testosterone suppression with luteinizing hormone-releasing hormone agonists: Does it happen and does it matter? BJU Int 110:E500-E507, 2012

4. Morote J, Orsola A, Planas J, et al: Redefining clinically significant castration levels in patients with prostate cancer receiving continuous androgen deprivation therapy. J Urol 178:1290-1295, 2007
5. Perachino M, Cavalli V, Bravi F: Testosterone levels in patients with metastatic prostate cancer treated with luteinizing hormone-releasing hormone therapy: Prognostic significance? BJU Int 105:648645, 2010

6. Bertaglia V, Tucci M, Fiori C, et al: Effects of serum testosterone levels after 6 months of androgen deprivation therapy on the outcome of patients with prostate cancer. Clin Genitourin Cancer 11:325330, 2013

7. Klotz LH, Herr HW, Morse MJ, et al: Intermittent endocrine therapy for advanced prostate cancer. Cancer 58:2546-2550, 1986

8. Abrahamsson PA: Potential benefits of intermittent androgen suppression therapy in the treatment of prostate cancer: A systematic review of the literature. Eur Urol 57:49-59, 2010

9. Crook JM, O'Callaghan CJ, Duncan G, et al: Intermittent androgen suppression for rising PSA level after radiotherapy. N Engl J Med 367:895-903, 2012
10. Hochberg Y: A sharp Bonferroni procedure for multiple tests of significance. Biometrics 75:800802, 1988

11. Tombal B, Berges R: Optimal control of testosterone: A clinical case based approach of modern androgen-deprivation therapy. Eur Urol 7:15-21, 2008 (suppl)

12. Mohler JL: Castration-recurrent prostate cancer is not androgen-independent. Adv Exp Med Biol 617:223-234, 2008

13. Hussain $M$, Tangen $C M$, Berry $D L$, et al: Intermittent versus continuous androgen deprivation in prostate cancer. N Engl J Med 368:13141325, 2013

14. Kawata $H$, Ishikura $N$, Watanabe $M$, et al: Prolonged treatment with bicalutamide induces androgen receptor overexpression and androgen hypersensitivity. Prostate 70:745-754, 2010

15. Klotz L, Toren P: Androgen deprivation therapy in advanced prostate cancer: Is intermittent therapy the new standard of care? Curr Oncol 19: S13-S21, 2012 (suppl 3) 


\section{AUTHORS' DISCLOSURES OF POTENTIAL CONFLICTS OF INTEREST}

Nadir Testosterone Within First Year of Androgen-Deprivation Therapy (ADT) Predicts for Time to Castration-Resistant Progression: A Secondary Analysis of the PR-7 Trial of Intermittent Versus Continuous ADT

The following represents disclosure information provided by authors of this manuscript. All relationships are considered compensated. Relationships are self-held unless noted. I = Immediate Family Member, Inst = My Institution. Relationships may not relate to the subject matter of this manuscript. For more information about ASCO's conflict of interest policy, please refer to www.asco.org/rwc or jco.ascopubs.org/site/ifc.

\section{Laurence Klotz}

Honoraria: Aventis, Astellas Pharma, Amgen, Janssen Pharmaceuticals, Abbvie

Research Funding: Ferring Pharmaceuticals (Inst)

\section{Chris O'Callaghan}

No relationship to disclose

\section{Keyue Ding}

No relationship to disclose

\section{Paul Toren}

No relationship to disclose

\section{David Dearnaley}

Patents, Royalties, Other Intellectual Property: Patent for localizing device; royalties for drug discovery

\section{Celestia S. Higano}

Employment: Cell Therapeutics (I)

Leadership: Cell Therapeutics (I)

Stock or Other Ownership: Cell Therapeutics (I)

Consulting or Advisory Role: Dendreon, Bayer, Medivation, Novartis, BHR Pharma, Ferring Pharmaceuticals, Johnson \& Johnson, AbbVie, Genentech, Astellas, Pfizer

Research Funding: Algeta/Bayer (Inst), Aragon (Inst), AstraZeneca (Inst), Dendreon (Inst), Genentech (Inst), Medivation (Inst),

Millennium Pharmaceuticals (Inst), sanofi-aventis (Inst), Teva (Inst)
Travel, Accommodations, Expenses: Bayer, Medivation, Novartis, Dendreon, Ferring Pharmaceuticals, Pfizer, Johnson \& Johnson, AbbVie, Genetech

Eric Horwitz

No relationship to disclose

Shawn Malone

No relationship to disclose

Larry Goldenberg

Leadership: Genyous (chief medical officer urology)

Stock or Other Ownership: Oncogenex

Honoraria: Amgen, Eli Lilly, Abbott, GlaxoSmithKline

Consulting or Advisory Role: Eli Lilly Canada, Abbott Canada, GlaxoSmithKline Canada

Mary Gospodarowicz

No relationship to disclose

Juanita M. Crook

Honoraria: Abbvie, Astellas

Consulting or Advisory Role: Astellas

Research Funding: Ferring Pharmaceuticals (Inst) 